\title{
Headspace Solid-Phase Microextraction/Gas Chromatography-Mass Spectrometry for the Determination of 2-Nonenal and Its Application to Body Odor Analysis
}

\author{
Keita Saito*(D), Yoshiyuki Tokorodani, Chihiro Sakamoto and Hiroyuki Kataoka
}

check for

updates

Citation: Saito, K.; Tokorodani, Y.; Sakamoto, C.; Kataoka, H. Headspace Solid-Phase Microextraction/Gas Chromatography-Mass Spectrometry for the Determination of 2-Nonenal and Its Application to Body Odor Analysis. Molecules 2021, 26, 5739. https://doi.org/10.3390/

molecules26195739

Academic Editor: Alireza Ghiasvand

Received: 2 September 2021

Accepted: 20 September 2021

Published: 22 September 2021

Publisher's Note: MDPI stays neutral with regard to jurisdictional claims in published maps and institutional affiliations.

Copyright: (c) 2021 by the authors. Licensee MDPI, Basel, Switzerland. This article is an open access article distributed under the terms and conditions of the Creative Commons Attribution (CC BY) license (https:// creativecommons.org/licenses/by/ $4.0 /)$.
School of Pharmacy, Shujitsu University, Nishigawara, Okayama 703-8516, Japan; sh1908055@outlook.jp (Y.T.); sh1909027@outlook.jp (C.S.); hkataoka@shujitsu.ac.jp (H.K.)

* Correspondence: ksaito@shujitsu.ac.jp

\begin{abstract}
The odors and emanations released from the human body can provide important information about the health status of individuals and the presence or absence of diseases. Since these components often emanate from the body surface in very small quantities, a simple sampling and sensitive analytical method is required. In this study, we developed a non-invasive analytical method for the measurement of the body odor component 2-nonenal by headspace solid-phase microextraction coupled with gas chromatography-mass spectrometry by selective ion monitoring. Using a StableFlex PDMS/DVB fiber, 2-nonenal was efficiently extracted and enriched by fiber exposition at $50{ }^{\circ} \mathrm{C}$ for $45 \mathrm{~min}$ and was separated within $10 \mathrm{~min}$ using a DB-1 capillary column. Body odor sample was easily collected by gauze wiping. The limit of detection of 2-nonenal collected in gauze was $22 \mathrm{pg}(\mathrm{S} / \mathrm{N}=3)$, and the linearity was obtained in the range of 1-50 ng with a correlation coefficient of 0.991 . The method successfully analyzed 2-nonenal in skin emissions and secretions and was applied to the analysis of body odor changes in various lifestyles, including the use of cosmetics, food intake, cigarette smoking, and stress load.
\end{abstract}

Keywords: body odor; 2-nonenal; wiping method; pasting method; solid-phase microextraction (HS-SPME); gas chromatography-mass spectrometry (GC-MS)

\section{Introduction}

Body odor may be an indicator of stress and lifestyle diseases, including psychosomatic disorders, and may be an obstacle to a healthy social life [1-4]. As people are reluctant to indicate that others have body odor and the judgment criteria are ambiguous, the development of an objective quantitative method to evaluate body odor is desired. Body odor components include fatty acids, spices, and sulfurous odors [3,4]. Secretions by sweat glands and sebaceous glands are derived from volatile components decomposed by skin bacteria as well as components external to the body $[3,4]$. Among these compounds are unsaturated aldehydes, such as 2-nonenal, which is produced by the oxidation and decomposition of 9-hexadecenoic acid secreted by the sebaceous glands [1] (Figure S1). 2-Nonenal is also known as the odor contained in foods such as fresh juice and beer, and several analytical methods have been reported [5-15]. To date, however, sampling and analytical methods required to quantitatively analyze body odor compounds have not been established, so the actual state and dynamics of their occurrence have not been fully determined $[3,4,16]$. As "odors" generated from the body surface are complex and quantitatively small, their components may be difficult to detect with an analytical instrument. Highly sensitive analytical methods with efficient sampling and pretreatment are therefore needed to separate, identify, and quantify odor compounds. Although stir bar sorptive extraction [10], single-drop microextraction [11], and headspace solid-phase microextraction (HS-SPME) [12] methods have been reported for the efficient preconcentration of 2-nonenal in foods, they have not yet been used for body odor analysis. A conventional sampling 
method of skin emissions and secretions consists of placing the palm of the hand in a PVF bag and collecting the generated gas [1], but this method has drawbacks, including a possible lack of airtightness and questions about quantitative sampling. Body odor compounds have also been analyzed by gas chromatography (GC) after headspace sampling or passive flux sampling $[1,17,18]$, but these methods have problems with cost and storage. The SPME, using a fused-silica fiber externally coated with an appropriate stationary phase, is an effective sample preparation technique for integrating several operations such as sample collection, extraction, analyte enrichment, and isolation from sample matrices and is easily coupled with GC $[4,19-21]$. It is fast, solvent-free, and cost-effective and can improve the detection limits.

2-Nonenal is produced by reactions between fatty acids and lipid peroxides and is involved in the intake of fats and foods rich in fatty acids and in the peroxidation of lipids [1]. Thus, this production and intake of this compound are associated with the generation of active oxygen species [2]. Drinking, smoking, stress, and other lifestyle factors may therefore affect 2-nonenal secretion and alter body odor. Therefore, the effects of internal and external factors such as dietary intake, cosmetic use, smoking, and stress on body odor changes were analyzed using the method developed in this study.

In this study, we developed an efficient sampling method for the collection of body odor and an HS-SPME coupled with GC-mass spectrometry (GC-MS) for the selective and sensitive analysis of 2-nonenal in skin emissions and secretions. The method was applied to the body odor analysis in various lifestyles.

\section{Results and Discussion}

\subsection{Detection of 2-Nonenal by Gas Chromatography-Mass Spectrometry}

Full scan mass spectrum was measured at an $m / z$ range from 30 to 150 amu in order to determine the selected monitoring ion (SIM) for 2-nonenal (Mw: 140 daltons). Figure 1a shows a typical total ion chromatogram of 2-nonenal fragments obtained by $1 \mu \mathrm{L}$ direct injection analysis of standard 2-nonenal (1 $\mu \mathrm{g} / \mathrm{mL}$ solution). 2-Nonenal was eluted as a single and symmetrical peak within 10 min using a DB-1 column. As shown in Figure 1b, no molecular ions peak was detected, but several fragment ion peaks produced by cleavage of the 2-nonenal structure were observed on the spectra. Among these fragment ions, $m / z=55[\mathrm{CH}=\mathrm{CHCHO}], m / z=83\left[\mathrm{CH}_{2} \mathrm{CH}_{2} \mathrm{CH}=\mathrm{CHCHO}\right.$, and $\left.m / z=111\left[\mathrm{CH}_{2} \mathrm{CH}_{2} \mathrm{CH}_{2} \mathrm{CH}_{2} \mathrm{CH}=\mathrm{CHCHO}\right]\right)$ were selected for SIM mode detection.

(a)

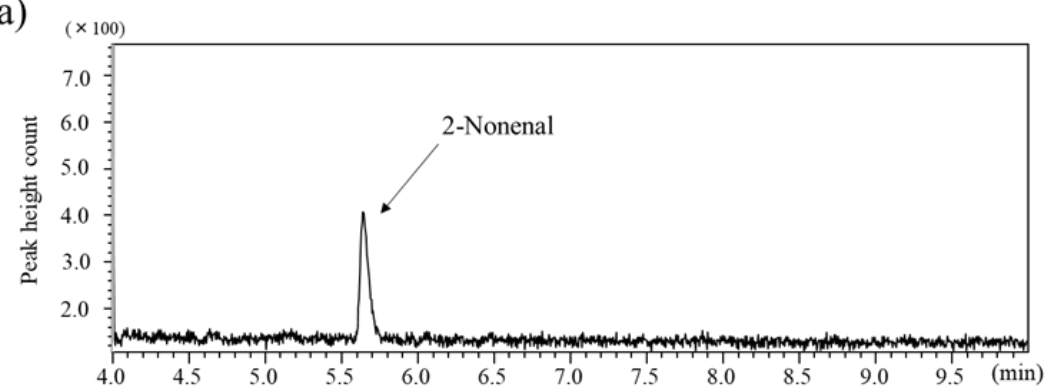

(b)

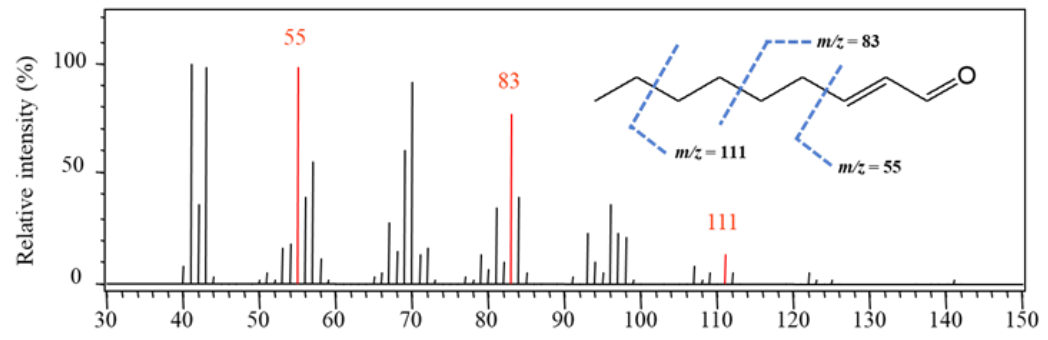

Figure 1. Chromatogram (a) and mass spectrum (b) obtained from standard 2-nonenal. The dotted lines in the structure represent the fragments of 2-nonenal. 


\subsection{Optimization of Headspace Solid-Phase Microextraction and Desorption}

In the SPME method, fiber coatings with high distribution coefficients must be used to increase the extraction efficiency of the compounds. To select an SPME fiber, the four different commercially available fibers (PDMS/DVB, DVB/CAR/PDMS, CAR/PDMS, and polyacrylate) were tested for extraction of $100 \mathrm{ng}$ of the 2-nonenal standard solution by HS-SPME. Of these fibers, the $65 \mu \mathrm{M}$ StableFlex PDMS/DVB fiber extracted 2-nonenal most efficiently (Figure 2A), and the fiber was used in subsequent experiments. To optimize HS-SPME extraction conditions, $100 \mathrm{ng}$ of 2-nonenal standard solution in a $40 \mathrm{~mL}$ vial was exposed to $65 \mu \mathrm{M}$ StableFlex PDMS/DVB fiber at various temperature and times. These experiments showed that 2-nonenal could be efficiently extracted and concentrated by exposing the fiber to the headspace at $50{ }^{\circ} \mathrm{C}$ (Figure 2B) for $45 \mathrm{~min}$ (Figure 2C). Although the extraction efficiency was highest at $30^{\circ} \mathrm{C}$, the extraction temperature set at $50{ }^{\circ} \mathrm{C}$ was less affected by the outside air temperature and could be kept. On the other hand, the time of the fiber exposition in the GC sample vaporization chamber at $230^{\circ} \mathrm{C}$ was tested to optimize the desorption condition. The 2-nonenal extracted on the fiber was easily desorbed within 5 min by heating in the GC sample vaporization chamber, and carryover was not observed because the fiber was washed during exposition.

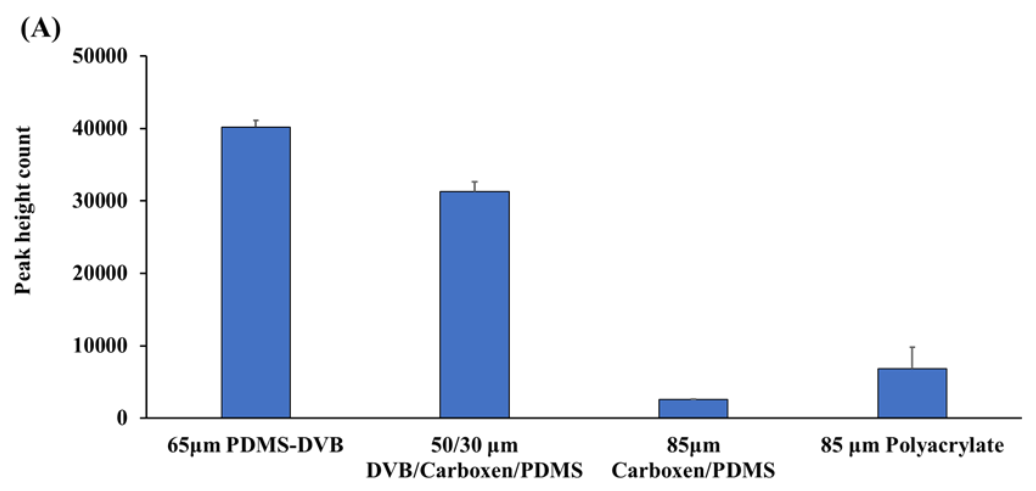

(B)

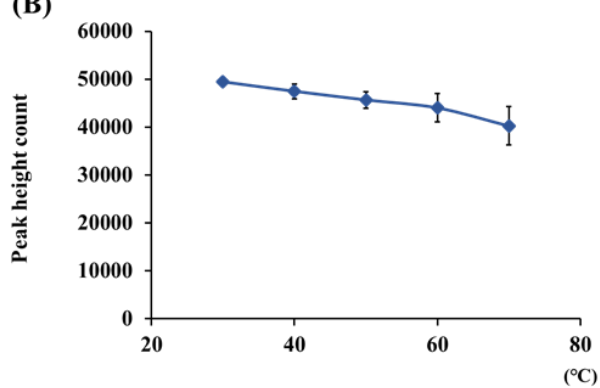

(C)

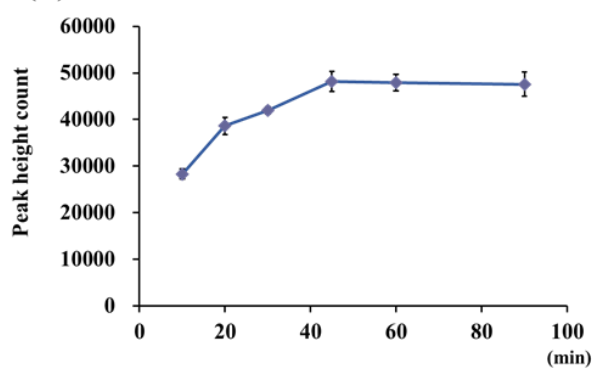

Figure 2. Effects of (A) fiber coatings, (B) temperature, and (C) time on the HS-SPME of 2-nonenal. For HS-SPME, $100 \mathrm{ng}$ of 2-nonenal in gauze was extracted by (A) fiber exposition at $50^{\circ} \mathrm{C}$ for $45 \mathrm{~min}$, (B) for 45 min with PDMS-DVB, and (C) at $50{ }^{\circ} \mathrm{C}$ with PDMS-DVB.

The absolute amount of 2-nonenal extracted by the HS-SPME method was calculated by comparing peak height count with direct injection onto the GC column. From the sample of $20 \mathrm{ng}$, $8.0 \mathrm{ng}$ (40\%) of 2-nonenal was extracted onto the PDMS/DVB fiber by HS-SPME under optimized conditions. Although the extraction yield was low, the reproducibility was good (relative standard deviation: $\operatorname{RSD}=4.7 \%, n=3$ ). Figure 3 shows the chromatograms obtained by direct injection and HS-SPME techniques. The sensitivity of the SPME method showed a 40-fold increase in sensitivity compared with when a solution of the same concentration was directly injected $(1 \mu \mathrm{L})$. 


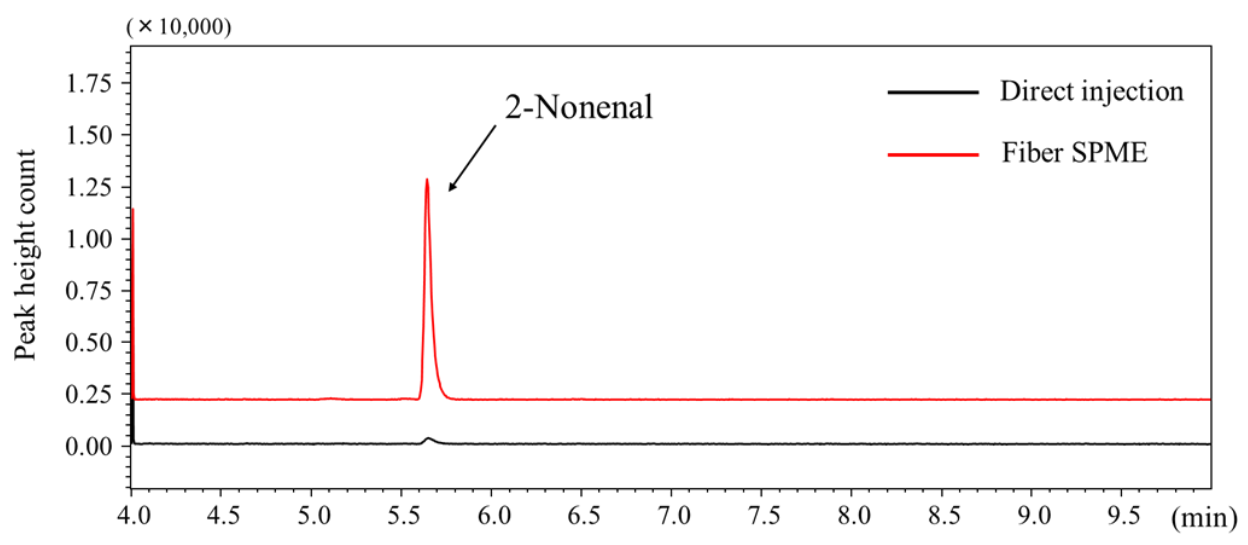

Figure 3. Typical total ion chromatogram of 2-nonenal obtained by (a) direct injection $(200 \mathrm{ng} / \mathrm{mL}$ solution, $1 \mu \mathrm{L})$ and HS-SPME (200 ng/mL solution, $100 \mu \mathrm{L}$ in 40-mL vial).

\subsection{Sampling of Skin Emissions and Secretions}

Four sampling methods (see the Materials and Methods section) for the collection of skin emissions and secretions from the palm were examined. As shown in Table 1, the wiping method (method C), in which the palm surface is wiped with gauze, was found to be the most efficient in collecting 2-nonenal. On the other hand, 2-nonenal was collected by the solution method (method A) using water in a cup and by the pasting method (method D) using gauze taped to the palm but not by the headspace method (method B) using HS-SPME directly in a suction cup. These results indicate that 2-nonenal released from the skin surface is difficult to collect from the headspace at body temperature and that active wiping is more effective than passive sampling, even when the sampling material is in direct contact with the skin. Therefore, the wiping method was used as the sampling method for the collection of skin emissions and secretions in this study. The recovery of 2 -nonenal from the gauze soaked with $5 \mathrm{ng}$ of 2-nonenal was about $60 \%$ compared to that of 2-nonenal added directly to the vial without gauze.

Table 1. Comparison of skin emission sampling methods.

\begin{tabular}{ccc}
\hline Classification & Sampling Method & $\begin{array}{c}\text { 2-Nonenal Content (ng) } \\
\text { Mean } \pm \text { SD }(\boldsymbol{n}=\mathbf{3})\end{array}$ \\
\hline A & Glass cup sampling & $0.47 \pm 0.51$ \\
B & Direct SPME sampling & N.D. \\
C & Wiping method & $0.90 \pm 0.13$ \\
D & Pasting method & $0.18 \pm 0.23$ \\
\hline
\end{tabular}

\footnotetext{
${ }^{1}$ N.D.: not detectable.
}

To examine the stability of 2-nonenal collected on gauze by the wiping method, $0.1 \mathrm{~g}$ of gauze soaked with $100 \mathrm{ng}$ of 2-nonenal was stored in vials at various times and temperatures, and the amount of 2-nonenal remaining on the gauze was determined by HS-SPME/GC-MS. As shown in Table 2, when stored at room temperature, there was almost no decrease in 2-nonenal up to $6 \mathrm{~h}$, but it was found to decrease to $60 \%$ at $24 \mathrm{~h}$. However, if the gauze was kept refrigerated at $4{ }^{\circ} \mathrm{C}$, there was almost no decrease even after $24 \mathrm{~h}$. Therefore, the gauze containing 2-nonenal collected by the wiping method should be kept refrigerated until analysis. 
Table 2. Comparison of storage conditions after sampling by the wiping method.

\begin{tabular}{ccc}
\hline Storage Condition $^{\mathbf{1}}$ & Storage Time (h) & $\begin{array}{c}\text { Peak Height Count } \\
\text { Mean } \pm \text { SD }(\boldsymbol{n}=3)\end{array}$ \\
\hline & 0 & $25,694 \pm 1486$ \\
Room temperature & 1 & $25,025 \pm 2830$ \\
& 2 & $24,537 \pm 1454$ \\
$4{ }^{\circ} \mathrm{C}$ (refrigerator) & 6 & $25,968 \pm 2162$ \\
& 24 & $24,208 \pm 3058$ \\
& 24 & $15,250 \pm 1600$ \\
\hline
\end{tabular}

${ }^{1}$ The gauze soaked with $50 \mathrm{ng}$ of 2-nonenal was stored in vials.

\subsection{Analytical Method Validation by Wiping Method}

To validate a proposed method based on the wiping sample collection, standard 2-nonenal placed in a petri dish was wiped with $0.1 \mathrm{~g}$ of dry gauze and analyzed by HS-SPME/GC-MS. Linearity was validated by triplicate analyses for 2-nonenal at 0, 1, 2, $5,10,20$, and $50 \mathrm{ng}$. The calibration curve was linear with a correlation coefficient of 0.991 , and the relative standard deviations (RSDs) of peak height counts at each point ranged from 1.8 to $9.6 \%(n=3)$. The LOD $(\mathrm{S} / \mathrm{N}=3)$ and LOQ $(\mathrm{S} / \mathrm{N}=10)$ of 2-nonenal in gauze were $22 \mathrm{pg}$ and $74 \mathrm{pg}$, respectively. Intra-day and inter-day precisions expressed as RSD (\%) were found to be 9.6 and $3.6 \%$, respectively. These results show that the method is highly sensitive and reproducible for the determination of 2-nonenal by the wiping method.

\subsection{Analyses of 2-Nonenal in the Body Odor Collected from Several Body Parts}

Body odor samples were collected by the wiping method from several body parts $6 \mathrm{~h}$ after washing with soap and then analyzed by HS-SPME/GC-MS. Figure 4 shows the 2nonenal content in body odor samples collected from the arms, axillae, back, chest, forehead, palm, and behind the ears of three subjects. Relatively high amounts of 2-nonenal were detected in the samples from the foreheads, arms, and ears, although this varied between individuals. To determine the amount of 2-nonenal secreted at different times of the day, body odor samples were collected from the forehead every $3 \mathrm{~h}$ by the wiping method and analyzed by HS-SPME/GC-MS. As shown in Figure 5, the secretion of 2-nonenal was highest between 13:00 and 16:00 in the afternoon (average contents of 2-nonenal from three people). The chromatogram of the 2-nonenal sampled from the forehead is shown in Figure 6. It was found that 2-nonenal was detected with clear separation and was not affected by the interfering peak.

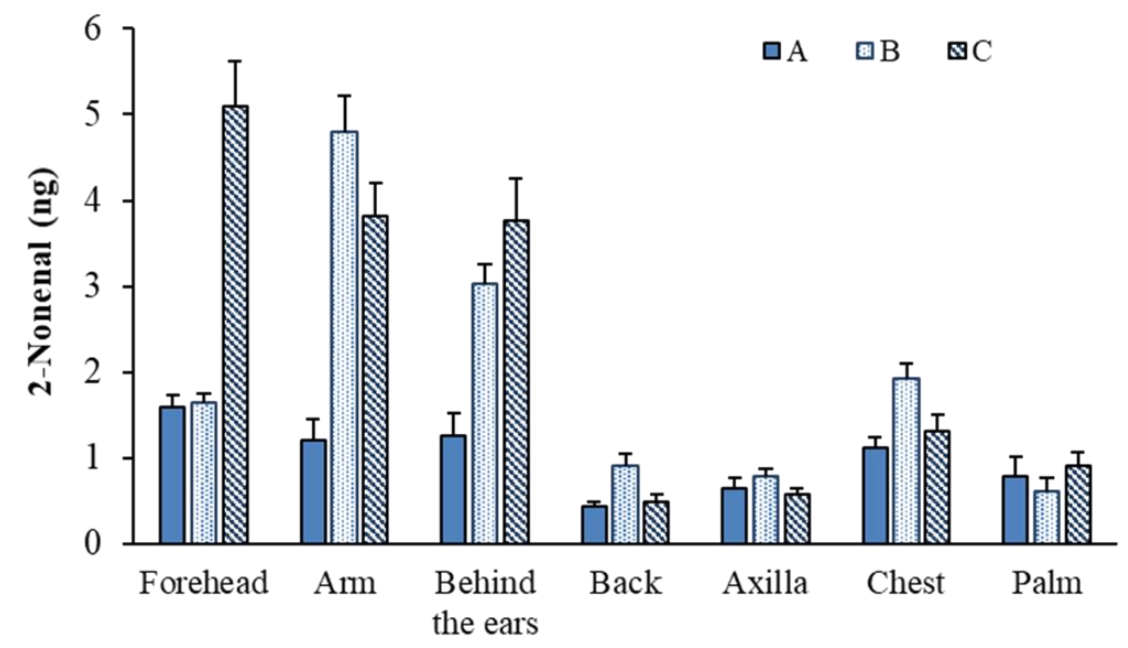

Figure 4. Comparison of 2-nonenal contents in body odor samples collected from several body parts (A: female in their $20 \mathrm{~s}, \mathrm{~B}$ : male in their $20 \mathrm{~s}, \mathrm{C}$ : male in their $30 \mathrm{~s}$ ). 


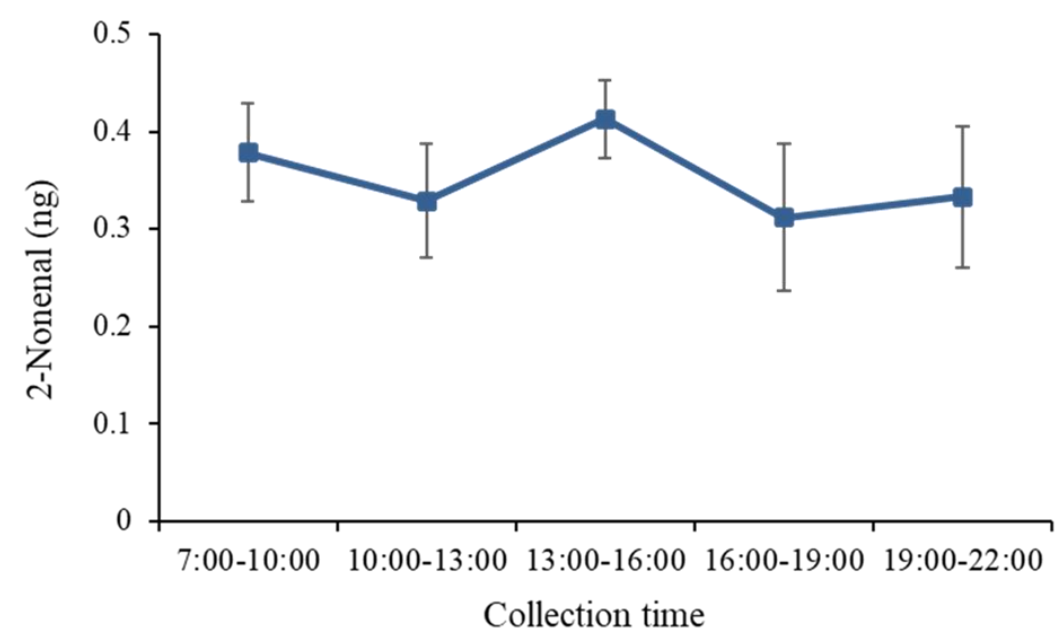

Figure 5. Circadian rhythm of 2-nonenal emission from skin (forehead) (average contents of 2-nonenal from three people).

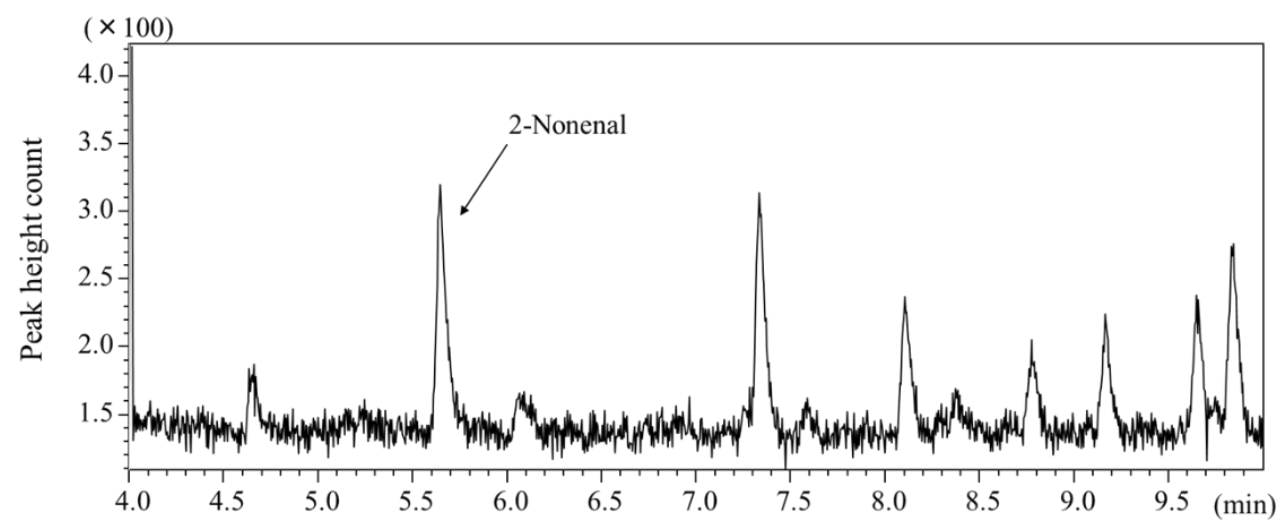

Figure 6. Total ion chromatogram of skin emission sample (forehead, male in their $30 \mathrm{~s}$ ).

\subsection{Application to the Analysis of Body Odor Changes in Various Lifestyles}

Table 3 shows the results of HS-SPME/GC-MS analysis of the samples collected from the forehead by the wiping method after a certain period of time after each treatment. 2-Nonenal secretion was significantly increased on the high-fat diet compared with the low-fat diet. 2-Nonenal secretion was also slightly increased in lotion use and smoking compared with non-use and non-smoking, but the difference was not statistically significant. In contrast, mental stress caused by long meetings significantly increased 2-nonenal secretion. This may be because stress-induced sweating increased the secretion of fatty acids and lipid peroxides from the sebaceous glands, increasing oxidative degradation of these compounds to 2-nonenal by indigenous bacteria on the body surface [1].

Table 3. 2-Nonenal contents detected in body odor samples in various life styles.

\begin{tabular}{cccc}
\hline Treatment & Sampling Time after Treatment & $\begin{array}{c}\text { 2-Nonenal Content (ng) } \\
\text { Mean } \pm \text { SD }(\boldsymbol{n}=3)\end{array}$ & $\begin{array}{c}\text { T-Test } \\
p \text { Value }\end{array}$ \\
\hline Low fat diet & 12 & $0.49 \pm 0.09$ & $p<0.05$ \\
High fat diet & 12 & $0.70 \pm 0.09$ & $p>0.05$ \\
Without using cosmetics & 6 & $0.23 \pm 0.04$ & $p>0.05$ \\
Using cosmetics & 6 & $0.26 \pm 0.08$ & \\
Before smoking & 2 & $0.27 \pm 0.08$ & $p<0.05$ \\
After smoking & 2 & $0.37 \pm 0.09$ & \\
Before meeting & 6 & $0.23 \pm 0.04$ & $0.35 \pm 0.09$ \\
After meeting & 6 & & \\
\hline
\end{tabular}




\section{Materials and Methods}

\subsection{Reagents and Materials}

2-Nonenal was purchased from Nacalai Tesque (Kyoto, Japan). Methanol and distilled water (LC-MS grade) were purchased from Kanto Chemical (Tokyo, Japan). A stock solution of $1 \mathrm{mg} \mathrm{mL}^{-1}$ of 2-nonenal was prepared by dissolving in methanol (LC-MS grade), tightly sealed, and stored at $4{ }^{\circ} \mathrm{C}$. This stock solution was diluted with distilled water (LC-MS grade) to the desired concentration prior to use. All other chemicals were of analytical grade.

SPME assemblies with a replaceable and reusable extraction fiber coated with StableFlexTM polydimethylsiloxane/divinylbenzene (PDMS/DVB, $65 \mu \mathrm{M}$ ), StableFlexTM carboxene/PDMS/DVB (DVB/CAR/PDMS, 50/30 $\mu \mathrm{M})$, (CAR/ PDMS, $85 \mu \mathrm{M})$, StableFlexTM CAR/PDMS $(85 \mu \mathrm{M})$, and polyacrylate $(85 \mu \mathrm{M})$ were purchased from Supelco (Supelco Japan, Tokyo). These fibers were conditioned in a GC injection port at adequate temperature prior to use. One fiber can be used repeatedly at least more than one hundred times.

\subsection{Gas Chromatography-Mass Spectrometry}

GC-MS analysis was performed in the scan and SIM modes on a Shimadzu QP-2010 (Kyoto, Japan)gas chromatograph-mass spectrometer in conjunction with a GCMS solution Ver.2 workstation. GC separation was performed using a fused-silica capillary column of cross-linked DB-1 (J\&W, Folsom, CA, USA: $60 \mathrm{~m} \times 0.25 \mathrm{~mm}$ i.d., $1.0 \mu \mathrm{M}$ film thickness) under the following operating conditions: injection and detective temperatures, $230^{\circ} \mathrm{C}$; column temperature, held at a temperature of $190^{\circ} \mathrm{C}$ for $2 \mathrm{~min}$ and increased to $230{ }^{\circ} \mathrm{C}$ at a rate of $5^{\circ} \mathrm{C} \mathrm{min}{ }^{-1}$; inlet helium carrier gas flow rate, $1 \mathrm{~mL} \mathrm{~min}{ }^{-1}$ maintained by an electronic pressure controller; and split ratio, 10:1. The electron impact (EI)-MS conditions were as follows: ion-source temperature, $230{ }^{\circ} \mathrm{C}$; ionizing voltage, $70 \mathrm{eV}$. The full scan mass spectra were obtained at an $\mathrm{m} / \mathrm{z}$ range from 40 to $150 \mathrm{amu}$. Selected ion monitoring (SIM) mode detection for 2-nonenal was selected at $m / z=55,83,111$. The peak height count was measured to construct calibration curve and to determine concentrations of 2-nonenal in samples.

\subsection{Headspace Solid-Phase Microextraction}

The sample was placed in a 40-mL screw-cap vial with a PTFE septum and heated on a hot plate at $50{ }^{\circ} \mathrm{C}$. The SPME needle was passed through the septum of the vial, and the fiber was exposed in the headspace (HS) above sample for $45 \mathrm{~min}$ to adsorb the compounds vaporized by heating. After extraction, the fiber was retracted into the needle, the needle was withdrawn and introduced directly into the GC-MS sample vaporization chamber to desorb the extracted compound by heating. Then, the fiber was retracted into the needle, the needle was removed from the sample vaporization chamber and used for the HS-SPME of the next sample. An outline of the procedure for extraction by HS-SPME and desorption for GC-MS analysis is shown in Figure S2.

\subsection{Sampling of Skin Emissions and Secretions}

Four sampling methods for the collection of skin emissions and secretions were compared. Figure 7 shows the sampling methods from the palm of the hand. Sampling was carried out $3 \mathrm{~h}$ after washing the skin surface with soap. In method A (solution method), $2 \mathrm{~mL}$ of distilled water were added to a glass cup, and the cup was inverted so that the water touched the skin on the palm of one hand for $5 \mathrm{~min}$. The aqueous solution was subjected to the above HS-SPME method. In method B (headspace method), a suction cup is placed on the palm, the SPME fiber needle is inserted through the septum into the cup under reduced pressure, and then, the fiber is exposed for 5 min to extract the skin emissions. In method C (wiping method), a $2 \mathrm{~cm}$ square area of the palm was wiped for $1 \mathrm{~min}$ with $0.1 \mathrm{~g}$ of dry gauze as a collecting material of skin emissions and secretions, which was then placed in a vial and subjected to the above HS-SPME method. In method 
$\mathrm{D}$ (pasting method), $0.1 \mathrm{~g}$ of dry gauze was taped to the palm and extracted for $3 \mathrm{~h}$. These collecting materials were then subjected to the HS-SPME as in method C.

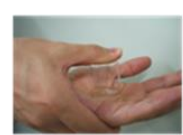

Method A

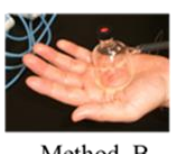

Method B

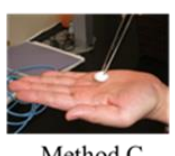

Method C

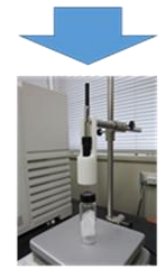

Extraction by SPME method

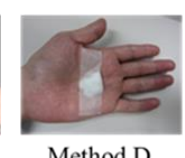

Method D

Figure 7. Sampling methods of skin emissions and secretions.

\subsection{Analysis of Body Odor Samples}

The experimental protocol was approved by the Research Ethics and Safety Committee of Shujitsu University, and body odor samples were provided from one female and two male subjects in their $20 \mathrm{~s}$ and $30 \mathrm{~s}$ by informed consent. The samples were collected from the arm, axilla, back, chest, forehead, palm, and behind the ears by method $\mathrm{C}$ described in the above section. 2-Nonenal in the body odor collected on the gauze was subsequently analyzed by HS-SPME/GC-MS. To analyze changes in body odor due to the various life styles, body odor samples were collected from the forehead by method $\mathrm{C}$ before and after treatments and analyzed by HS-SPME/GC-MS as described above. As a concrete examination, we compared before and after food intake (eating $200 \mathrm{~g}$ of vegetables for the low fat diet or $200 \mathrm{~g}$ of beef for the high fat diet, sampling $12 \mathrm{~h}$ later), using cosmetics (applying $1 \mathrm{~mL}$ lotion to face, sampling $6 \mathrm{~h}$ later), smoking (smoking one cigarette, sampling $2 \mathrm{~h}$ later), and a $3 \mathrm{~h}$ meeting as a stress load (sampling $6 \mathrm{~h}$ later).

\section{Conclusions}

The method developed in this study can easily collect 2-nonenal, a component of human body odor, from the skin surface by gauze wiping and can be selectively and sensitively analyzed by HS-SPME/GC-MS. Gauze wiping is a rapid and non-invasive sampling method for skin emissions and secretions and has better storage stability than other tested methods. As shown in Table 4, the proposed method is more sensitive than previously reported methods, even when converted into the skin surface area and the amount of recovery per hour. We believe that this method is a useful tool for 2-nonenal analysis in body odor. Although this study focused on 2-nonenal, body odor is a complex mixture of compounds, and therefore, it is necessary to analyze not only 2-nonenal but also a wide range of related compounds in the future. The method developed in this study may be applicable to their comprehensive analysis.

Table 4. Comparison of analytical methods for 2-nonenal and other aldehydes in body odor.

\begin{tabular}{|c|c|c|c|c|}
\hline Compounds & Analytical Method & Sampling and Preconcentration & Detection Amount & Reference \\
\hline 2-Nonenal & GC-MS & Tedlar bag and TENAX-TA column & $15.1 \pm 20.4 \mathrm{ng} \cdot \mathrm{cm}^{-3(1)}$ & [1] \\
\hline $\begin{array}{c}\text { Five aldehydes and } \\
\text { acetone }\end{array}$ & HPLC-UV & $\begin{array}{c}\text { Passive flux sampler } \\
\text { (trapping filter: DNPH impregnated } \\
\text { filter) }\end{array}$ & $17 \mathrm{ng} \cdot \mathrm{cm}^{-2} \cdot \mathrm{h}^{-1(2)}$ & [17] \\
\hline $\begin{array}{l}\text { 2-Nonenal and } \\
\text { diacetyl }\end{array}$ & GC-MS & $\begin{array}{l}\text { Passive flux sampler } \\
\text { (trapping media: Monotrap, DCC18) }\end{array}$ & 0.020 to $5.8 \mathrm{ng} \cdot \mathrm{cm}^{-2} \cdot \mathrm{h}^{-1(3)}$ & [18] \\
\hline 2-Nonenal & GC-MS & $\begin{array}{c}\text { Fiber SPME } \\
\text { (Wiping method) }\end{array}$ & $2.4 \mathrm{pg} \cdot \mathrm{cm}^{-2} \cdot \mathrm{h}^{-1(4)}$ & This study \\
\hline
\end{tabular}

\footnotetext{
(1) Sampling from the back of the shirt worn for 3 days; ${ }^{(2)}$ Sampling from the surface of human skin, sampling time $1 \mathrm{~h}$, aldehydes (LOD);
}

(3) Sampling from the nape of the neck, sampling time $7 \mathrm{~h}$; ${ }^{(4)} \mathrm{LOD}$. 
Supplementary Materials: The following are available online. Figure S1: Presumed formation mechanism of 2-nonenal by lipid peroxidation. Data from Haze et al., 2001 [1], Figure S2: Procedure for extraction by headspace fiber SPME and desorption for GC-MS analysis. Data from Kataoka and Saito, 2011 [20].

Author Contributions: Conceptualization, K.S. and H.K.; methodology, K.S. and H.K.; software, K.S. and H.K.; validation, K.S. and H.K.; formal analysis, Y.T., C.S., and K.S.; investigation, K.S. and H.K.; resources, K.S. and H.K.; data curation, Y.T., C.S., and K.S.; writing-original draft preparation, K.S. and H.K.; writing-review and editing, K.S.; visualization, K.S. and H.K.; supervision, K.S.; project administration, K.S. All authors have read and agreed to the published version of the manuscript.

Funding: This research received no external funding.

Institutional Review Board Statement: The study was conducted according to the guidelines of the Declaration of Helsinki and was approved by the ethics committee of Shujitsu University.

Informed Consent Statement: Informed consent was obtained from all subjects involved in the study.

Data Availability Statement: The data presented in this study are available from the corresponding author upon request.

Conflicts of Interest: The authors declare no conflict of interest.

Sample Availability: Samples of the compounds are not available from the authors.

\section{References}

1. Haze, S.; Gozu, Y.; Nakamura, S.; Kohno, Y.; Sawano., K.; Ohta, H.; Yamazaki, K. 2-Nonenal newly found in human body odor tends to increase with aging. J. Investig. Dermatol. 2001, 116, 520-524. [CrossRef] [PubMed]

2. Ishino, K.; Wakita, C.; Shibata, T.; Toyokuni, S.; Machida, S.; Matsuda, S.; Matsuda, T.; Uchida, K. Lipid peroxidation generates body odor component trans-2-nonenal covalently bound to protein in vivo. J. Biol. Chem. 2010, 285, 15302-15313. [CrossRef] [PubMed]

3. Pandey, S.K.; Kim, K.H. Human body-odor components and their determination. Trends Anal. Chem. 2011, 30, 784-796. [CrossRef]

4. Kataoka, H.; Saito, K.; Kato, H.; Masuda, K. Non-invasive analysis of volatile biomarkers in human emanations for health and early disease diagnosis. Bioanalysis 2013, 5, 1443-1459. [CrossRef] [PubMed]

5. Santos, J.R.; Carneiro, J.R.; Guido, L.F.; Almeida, P.J.; Rodrigues, J.A.; Barros, A.A. Determination of E-2-nonenal by highperformance liquid chromatography with UV detection assay for the evaluation of beer ageing. J. Chromatogr. A 2003, 985, 395-402. [CrossRef]

6. Guido, L.F.; Carneiro, J.R.; Santos, J.R.; Almeida, P.J.; Rodrigues, J.A.; Barros, A.A. Simultaneous determination of E-2-nonenal and beta-damascenone in beer by reversed-phase liquid chromatography with UV detection. J. Chromatogr. A 2004, 1032, 17-22. [CrossRef] [PubMed]

7. Kuroda, H.; Kojima, H.; Kaneda, H.; Takashio, M. Characterization of 9-fatty acid hydroperoxide lyase-like activity in germinating barley seeds that transforms 9(S)-hydroperoxy-10(E),12(Z)-octadecadienoic acid into 2(E)-nonenal. Biosci. Biotechnol. Biochem. 2005, 69, 1661-1668. [CrossRef]

8. Chen, Q.; Song, J.; Bi, J.; Meng, X.; Wu, X. Characterization of volatile profile from ten different varieties of Chinese jujubes by HS-SPME/GC-MS coupled with E-nose. Food Res. Int. 2018, 105, 605-615. [CrossRef]

9. Liu, Y.; He, C.; Song, H. Comparison of fresh watermelon juice aroma characteristics of five varieties based on gas chromatographyolfactometry-mass spectrometry. Food Res. Int. 2018, 107, 119-129. [CrossRef]

10. Ochiai, N.; Sasamoto, K.; Daishima, S.; Heiden, A.C.; Hoffmann, A. Determination of stale-flavor carbonyl compounds in beer by stir bar sorptive extraction with in-situ derivatization and thermal desorption-gas chromatography-mass spectrometry. $J$. Chromatogr. A 2003, 986, 101-110. [CrossRef]

11. Ligor, T.; Buszewski, B. Single-drop microextraction and gas chromatography-mass spectrometry for the determination of volatile aldehydes in fresh cucumbers. Anal. Bioanal. Chem. 2008, 391, 2283-2289. [CrossRef] [PubMed]

12. Olivero, S.J.P.; Trujillo, J.P.P. A new method for the determination of carbonyl compounds in wines by headspace solid-phase microextraction coupled to gas chromatography-ion trap mass spectrometry. J. Agric. Food Chem. 2010, 58, 12976-12985. [CrossRef] [PubMed]

13. Carrillo, G.; Bravo, A.; Zufall, C. Application of factorial designs to study factors involved in the determination of aldehydes present in beer by on-fiber derivatization in combination with gas chromatography and mass spectrometry. J. Agric. Food Chem. 2011, 59, 4403-4411. [CrossRef] [PubMed]

14. Bi, S.; Sun, S.; Lao, F.; Liao, X.; Wu, J. Gas chromatography-mass spectrometry combined with multivariate data analysis as a tool for differentiating between processed orange juice samples on the basis of their volatile markers. Food Chem. 2020, 311, 125913. [CrossRef] [PubMed] 
15. Tsuzuki, S. Higher Straight-Chain Aliphatic Aldehydes: Importance as Odor-Active Volatiles in Human Foods and Issues for Future Research. J. Agric. Food Chem. 2019, 67, 4720-4725. [CrossRef] [PubMed]

16. Jiang, R.; Cudjoe, E.; Bojko, B.; Abaffy, T.; Pawliszyn, J. A non-invasive method for in vivo skin volatile compounds sampling. Anal. Chim. Acta 2013, 804, 113-119. [CrossRef] [PubMed]

17. Sekine, Y.; Toyooka, S.; Watts, S.F. Determination of acetaldehyde and acetone emanating from human skin using a passive flux sampler-HPLC system. J. Chromatogr. B 2007, 859, 201-207. [CrossRef] [PubMed]

18. Kimura, K.; Sekine, Y.; Furukawa, S.; Takahashi, M.; Oikawa, D. Measurement of 2-nonenal and diacetyl emanating from human skin surface employing passive flux sampler-GCMS system. J. Chromatogr. B 2016, 1028, 181-185. [CrossRef] [PubMed]

19. Kataoka, H. Recent developments and applications of microextraction techniques in drug analysis. Anal. Bioanal. Chem. 2010, 396, 339-364. [CrossRef]

20. Kataoka, H.; Saito, K. Recent advances in SPME techniques in biomedical analysis. J. Pharm. Biomed. Anal. 2011, 54, 926-950. [CrossRef]

21. Kataoka, H.; Ishizaki, A.; Saito, K. Recent progress in solid-phase microextraction and its pharmaceutical and biomedical applications. Anal. Methods 2016, 8, 5773-5788. [CrossRef] 